\title{
An initial genetic characterisation of the grape powdery mildew (Erysiphe necator) in New Zealand associated with recent reports of the sexual stage
}

\author{
J.A. Cooper ${ }^{1}$, D. Park ${ }^{2}$ and P.R. Johnston ${ }^{2}$ \\ ${ }^{1}$ Landcare Research, PO Box 69040, Lincoln 7640, New Zealand \\ ${ }^{2}$ Landcare Research, Private Bag 92170, Auckland 1142, New Zealand \\ Corresponding author:CooperJ@LandcareResearch.co.nz
}

\begin{abstract}
The asexual form of the grape powdery mildew, Erysiphe necator, has been present in New Zealand for over 100 years. In 2013 the sexual stage was reported for the first time in vineyards in Hawke's Bay associated with increased disease issues. This paper presents an initial genetic analysis of New Zealand populations compared to known populations overseas and tentatively identifies two haplotypes new to New Zealand. Initial analysis of mating-type ratios indicates only one of these haplotypes is sexually reproducing. A better understanding of the fundamental character of the New Zealand populations of Erysiphe necator is needed before an accurate assessment can be made of the practical impact that the introduction of the sexual stage has had on disease incidence and control.
\end{abstract}

Keywords grape powdery mildew, Erysiphe necator, population structure, chasmothecia.

\section{INTRODUCTION}

The powdery mildew Erysiphe necator has been present in New Zealand for over 100 years (Gadgil 2005). Until recently it has been recorded in its asexual form only, in which it produces large numbers of asexual spores (conidia) throughout the growing season, which give the fungus its common name. Erysiphe necator is capable of surviving from year to year in this asexual form, as dormant mycelium within buds (Gadoury et al. 2012b) that are capable of re-starting the asexual cycle in the following season. The buds may form characteristic 'flag shoots' with infection developing early in the following season (Gadoury et al. 2012b).

In 2013 the sexual state was recorded in New Zealand for the first time in Hawke's Bay (P.N. Wood, Plant \& Food Research, personal communication; Johnston et al. 2014). The sexual state is manifest by chasmothecia (previously termed cleistothecia). These are the small, globose sexual fruitbodies that form towards the end of the season on the surface of the hyphal mat of the powdery mildew present on leaves and berries (Figure 1a \& 1b). As they mature they darken from yellow to black and are adapted to survival over winter on bark and litter. The chasmothecia contain ascospores within asci, which are released and germinate under suitable conditions. The occurrence of the sexual state in New Zealand has been accompanied by a reported increase in the severity of the disease by growers (P.N. Wood, personal communication).

There are two key questions relating to the disease in New Zealand: (1) Does the recent observation of chasmothecia indicate a recent incursion of a strain not previously 

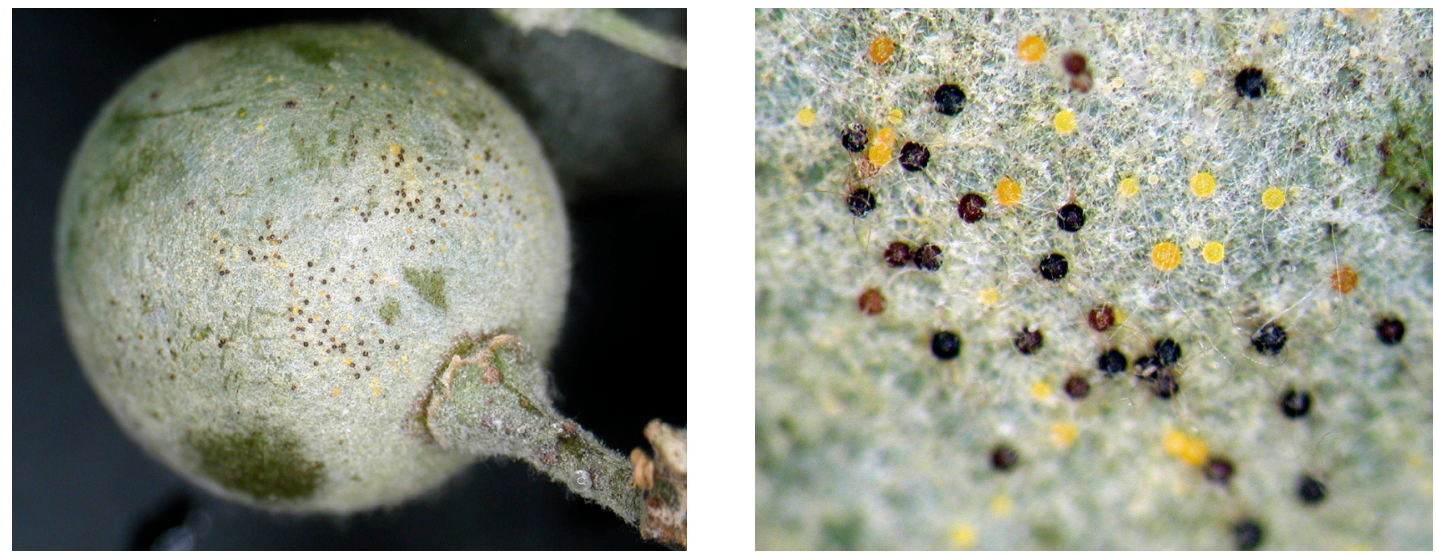

Figure 1 Chasmothecia of Erysiphe necator (a) associated with the hyphal mat on the surface of a berry, and (b) detail of chasmothecia, with individial chasmothecia being approximately $2 \mathrm{~mm}$ diameter.

present, or is their appearance due to recent changes in environmental conditions and/or control measures? and (2) Is the appearance of chasmothecia causally linked to increases in disease severity as a consequence of changed life-cycle or is there a more fundamental genetic change in the virulence of one or more strains? Findings from overseas suggest the formation of chasmothecia is directly associated with increased disease severity (Gadoury et al. 2012b). In this initial study, techniques developed to characterise Erysiphe necator elsewhere have been applied to a small sample of New Zealand isolates. This work does not answer the questions posed above, but demonstrates informative baseline data can be collected through molecular-based approaches and indicates further work is necessary.

Erysiphe necator originated on wild relatives of Vitis vinifera in the United States (Brewer \& Milgroom 2010). It dispersed from the USA over 160 years ago to infect vines in Europe and subsequently in other parts of the world. In many countries the same pattern has emerged of a long period with the asexual form only, followed by the occurrence of the sexual form many years later (e.g. Araya et al. 2014). These two states of the disease have been historically associated with genetically different and co-located populations, termed Group A for the asexual form and Group B for the sexual form (Brewer \& Milgroom 2010).
The population structure of the fungus was first studied in detail using molecular methods by Brewer \& Milgroom (2010). They investigated the variation at 37 nucleotide positions within four loci: Internal Transcribed Spacer (ITS), Intergenic Spacer (IGS), Beta Tubulin (TUB2) and Translation Elongation Factor 1- $\alpha$ $(\mathrm{EF}-1 \alpha)$. These positions were indicated relative to standard sequences deposited in GenBank (ITS: GQ255473, IGS: GQ255476, TUB2: GQ255475, EF-1 $\alpha$ : GQ255471). Brewer \& Milgroom (2010) analysed 146 isolates from the USA on vines and wild vine relatives, and isolates from Europe and Australia. Analysis of the resulting variability showed a network containing 45 haplotypes with most of these present within the USA only. A single haplotype present in Europe and Australia (designated Haplotype 33) was equated with the asexual population Group A, whereas five haplotypes (designated Haplotypes 41-45) were equated with the sexual Group B population also present in Europe and Australia.

In fungi, the sexual cycle-from the recognition of a potential mate to the development of sexual structures and recombination - is regulated by genes at mating type loci. Powdery mildews are known to possess a single mating type locus (MAT1) with two variants. The variants are termed idiomorphs rather than alleles to reflect the fact they encode different genes. The idiomorphs are labelled MAT1-1 and MAT1-2 
(Brewer et al.2011). For chasmothecia to form and the sexual cycle to complete, colonies containing both these mating types must be present and meet. The fungus can survive asexually, and with populations containing just a single idiomorph, which is the case for most Group A populations (Gadoury et al. 2012a). In sexually recombining populations under equilibrium single-conidia isolates should contain about equal numbers of MAT1-1 and MAT1-2 mating types.

This paper reports an initial genetic analysis of New Zealand populations of E. necator to determine the correspondence between New Zealand isolates and the 45 haplotypes determined by Brewer \& Milgroom (2010), and also an initial test of the technique to determine mating type structure in New Zealand populations.

\section{MATERIALS AND METHODS}

The genetic characterisation methodology reported by Brewer \& Milgroom (2010) was adopted. Samples $(n=38)$ were collected from single blocks of a number of grape cultivars in vineyards in Auckland, Hawke's Bay, Gisborne, Nelson, Marlborough and Central Otago. Severity of infection within the sampled vineyards was recorded annecdotally, based on the respective viticulturalist's observations. In addition table-grape cultivars present in two gardens in Christchurch were sampled. Two samples were collected in 2014, including the first recorded collection with chasmothecia from Hawke's Bay (PF8; voucher specimen stored in the New Zealand Fungal and Plant Disease Collection as PDD 104194), and the remainder were sampled between February and March 2015 (including PDD 105484 and 107779).

Conidia and hyphae from lesions of E. necator on the surface of berries and leaves were scraped onto non-indicating FTA micro-cards (Whatman, GE Healthcare Life Sciences) for preservation before extraction, amplification and sequencing. Sampling was directly from single lesions on material collected directly from vineyards rather than from subsequent single conidia isolates propagated on sterile leaf surfaces in vitro. The genomic DNA extraction and PCR were performed on $2 \mathrm{~mm}$ diameter punch from each FTA card using REDExtract-N-Amp Plant PCR kits (SigmaAldrich, USA) according to the manufacturer's protocol with a minor modification.

All of the samples (except PF8) exhibited the asexual conidia only (but may have formed chasmothecia later in the season). Under these conditions many samples showed contamination by other fungi. The ITS region proved particularly difficult to sequence and was excluded from down-stream analysis. In addition, sequences of amplicons sometimes indicated ambiguous base calls at two nucleotide positions (IGS: 206, TUB2: 316), and these were also excluded from down-stream analysis. The samples showed unambiguous variation at six remaining sites (IGS: 108, 216, 223; TUB2: 79; EF-1 $\alpha$ : 336, 420). The New Zealand data were combined with those from Brewer \& Milgroom (2010) for the subset of isolates from Vitis vinifera. The resulting data matrix contained variants at 19 sites in total. A phylogenetic network was constructed using SplitsTree4 (Hudson \& Bryant 2006). The network was built by the NeighborNet method using uncorrected-p distances and averaging over ambiguous states. Bootstrap values were obtained with 1000 replicates.

The methodology of Brewer et al. (2011), who developed a PCR-based marker for determining the mating type idiomorph present at the MAT1 locus, was adopted for the initial analysis of mating types. This test was applied to a limited number of samples (16) that were collected in January 2015 from two vineyards in Auckland.

\section{RESULTS}

The polymorphism at the 19 nucleotide positions is shown for the New Zealand samples (Table 1) and for isolates from Vitis vinifera from USA, Europe and Australia (Brewer \& Milgroom 2010), excluding ITS and sites recognised as ambiguous in New Zealand samples (Table 2). The New Zealand data indicate three fully characterised groups within New Zealand that have been labelled B-NZ1, B-NZ2 and A-33. Another potential group lacking sufficient data to characterise with certainty was detected on a leaf sample from a table grape variety in Christchurch and from a Nelson sample. 
Table 1 Single nucleotide polymorphisms for New Zealand samples. Dashes indicate same nucleotide as Brewer \& Milgroom (2010) Haplotype 33 (line 1). IGS nucleotide positions 108, 216, 223; TUB2 nucleotide positions 24, 37, 79, 288, 356, 368; EF-1 $\alpha$ nucleotide positions 2, 9, 33, 102, 189, 228, 231, 336, 384, 420.

\begin{tabular}{|c|c|c|c|c|c|}
\hline Location $^{1}$ (isolate) & $\begin{array}{l}\text { Year } \\
\text { sampled }\end{array}$ & Group & IGS & TUB2 & EF- $1 \alpha$ \\
\hline Haplotype 33 & - & - & CCT & TGTACC & CTGACTTTGC \\
\hline $\mathrm{AK}(\mathrm{BB} 1)$ & 2015 & $\mathrm{~B}-\mathrm{NZ1}$ & TTC & $--\mathrm{C}---$ & $---------T$ \\
\hline $\mathrm{AK}(\mathrm{BB} 2)$ & 2015 & $\mathrm{~B}-\mathrm{NZ1}$ & TTC & $--\mathrm{C}---$ & $---------T$ \\
\hline $\mathrm{AK}(\mathrm{BB} 3)$ & 2015 & $\mathrm{~B}-\mathrm{NZ1}$ & TTC & $--\mathrm{C}---$ & $---------T$ \\
\hline $\mathrm{AK}(\mathrm{BB} 4)$ & 2015 & B-NZ1 & TTC & $--\mathrm{C}---$ & ---------T \\
\hline AK (BB5) & 2015 & $\mathrm{~B}-\mathrm{NZ1}$ & TTC & $--\mathrm{C}---$ & $---------T$ \\
\hline $\mathrm{AK}(\mathrm{BB} 6)$ & 2015 & B-NZ1 & TTC & $--\mathrm{C}---$ & $---------T$ \\
\hline $\mathrm{AK}(\mathrm{BB} 7)$ & 2015 & $\mathrm{~B}-\mathrm{NZ1}$ & TTC & $--\mathrm{C}---$ & $---------T$ \\
\hline $\mathrm{AK}(\mathrm{VM} 1)$ & 2015 & B-NZ2 & TTC & $--\mathrm{C}---$ & $-------C-T$ \\
\hline $\mathrm{AK}(\mathrm{VM} 2)$ & 2015 & $\mathrm{~B}-\mathrm{NZ2}$ & TTC & $--\mathrm{C}---$ & $-------C-T$ \\
\hline AK (VM3) & 2015 & B-NZ2 & TTC & $--\mathrm{C}---$ & $-------C-T$ \\
\hline $\mathrm{AK}(\mathrm{VM} 4)$ & 2015 & $\mathrm{~B}-\mathrm{NZ2}$ & TTC & $--\mathrm{C}---$ & $-------C-T$ \\
\hline AK (VM5) & 2015 & B-NZ2 & TTC & $--\mathrm{C}---$ & $-------C-T$ \\
\hline AK (VM6) & 2015 & $\mathrm{~B}-\mathrm{NZ2}$ & TTC & $--\mathrm{C}---$ & $-------C-T$ \\
\hline AK (VM7) & 2015 & B-NZ2 & TTC & $--\mathrm{C}---$ & $-------C-T$ \\
\hline AK (VM9) & 2015 & $\mathrm{~B}-\mathrm{NZ2}$ & TTC & $--\mathrm{C}---$ & $-------C-T$ \\
\hline AW (A) & 2015 & B-NZ2 & TTC & $--\mathrm{C}---$ & $-------C-T$ \\
\hline CC (BS A) & 2015 & A-33 & --- & & ----------- \\
\hline CC (BS B) & 2015 & A-33 & --- & & ---------- \\
\hline CC (JAC13212) & 2014 & A-33 & --- & ------ & ---------- \\
\hline CC (JAC berry) & 2015 & A-33 & --- & ------ & ---------- \\
\hline CC (JAC leaf) & 2015 & $?$ & $\mathrm{~T}--$ & & ---------- \\
\hline $\mathrm{CO}(\mathrm{A})$ & 2015 & $\mathrm{~B}-\mathrm{NZ1}$ & TTC & & $---------T$ \\
\hline $\mathrm{CO}(\mathrm{B})$ & 2015 & $\mathrm{~B}-\mathrm{NZ1}$ & TTC & & ---------T \\
\hline GB (A) & 2015 & B-NZ2 & TTC & $--\mathrm{C}---$ & $-------C-T$ \\
\hline GB (B) & 2015 & $\mathrm{~B}-\mathrm{NZ2}$ & TTC & $--\mathrm{C}---$ & $-------C-\mathrm{T}$ \\
\hline GB (K'tiri A) & 2015 & $\mathrm{~B}-\mathrm{NZ2}$ & TTC & $--\mathrm{C}---$ & $-------C-T$ \\
\hline GB (K'tiri B) & 2015 & $\mathrm{~B}-\mathrm{NZ2}$ & & & $-------\mathrm{C}-\mathrm{T}$ \\
\hline HB (PFB) & 2014 & B-NZ2 & TTC & $--\mathrm{C}---$ & $-------C-T$ \\
\hline MB (Chard) & 2015 & $\mathrm{~B}-\mathrm{NZ2}$ & TTC & $--\mathrm{C}---$ & $-------C-\mathrm{T}$ \\
\hline MB (CV1006) & 2015 & B-NZ2 & TTC & $--\mathrm{C}---$ & $-------C-T$ \\
\hline MB (CV95A) & 2015 & B-NZ2 & TTC & $--\mathrm{C}---$ & $-------C-T$ \\
\hline MB (Riesling) & 2015 & $\mathrm{~B}-\mathrm{NZ1}$ & TTC & $--\mathrm{C}---$ & $---------T$ \\
\hline $\mathrm{NN}(\mathrm{A})$ & 2015 & $\mathrm{~B}-\mathrm{NZ1}$ & TTC & & $---------T$ \\
\hline $\mathrm{NN}(\mathrm{B})$ & 2015 & $\mathrm{~B}-\mathrm{NZ1}$ & TTC & & $---------T$ \\
\hline $\mathrm{NN}(\mathrm{C})$ & 2015 & B-NZ1 & TTC & $--\mathrm{C}---$ & ---------T \\
\hline NN (D) & 2015 & $\mathrm{~B}-\mathrm{NZ1}$ & TTC & & $---------T$ \\
\hline $\mathrm{NN}(\mathrm{E})$ & 2015 & $\mathrm{~B}-\mathrm{NZ1}$ & TTC & & $---------T$ \\
\hline $\mathrm{NN}(\mathrm{F})$ & 2015 & $?$ & $\mathrm{~T}--$ & & ---------- \\
\hline
\end{tabular}

${ }^{1} \mathrm{AK}=$ Auckland; $\mathrm{AW}=$ Awatere; $\mathrm{CC}=$ Christchurch; $\mathrm{CO}=$ Central Otago; $\mathrm{GB}=$ Gisborne; $\mathrm{HB}=$ Hawke's Bay; $\mathrm{MB}=$ Marlborough; $\mathrm{NN}=$ Nelson.

$?=$ insufficient data obtained. 
Table 2 Brewer \& Milgroom (2010) data, showing single nucleotide polymorphisms for the haplotypes recognised from Vitis vinifera from the USA ( $\mathrm{SE}=$ South-East USA, NE=North-East USA, C=Central USA, W=Western USA), Europe (EU) and Australia (AU).

\begin{tabular}{|c|c|c|c|c|}
\hline Haplotype & Distribution & IGS & TUB2 & EF1a \\
\hline 33 & SE, EU, AU & $\mathrm{CCT}$ & TGTACC & СTGACTTTGC \\
\hline 1 & SE, NE & $-\mathrm{TC}$ & $--\mathrm{C}---$ & ---------- \\
\hline 2 & $\mathrm{NE}$ & $-\mathrm{TC}$ & $--\mathrm{C}---$ & $-----\mathrm{C}----$ \\
\hline 9 & SE, NE & $-\mathrm{TC}$ & $--\mathrm{C}---$ & ---------T \\
\hline 11 & $\mathrm{SE}, \mathrm{C}, \mathrm{NE}$ & $-\mathrm{TC}$ & $--\mathrm{C}---$ & $--\mathrm{T}------\mathrm{T}$ \\
\hline 12 & SE, NE & $-\mathrm{TC}$ & $--\mathrm{C}---$ & $-------C-T$ \\
\hline 13 & $\mathrm{NE}$ & $-\mathrm{TC}$ & $--\mathrm{C}---$ & $---\mathrm{G}---\mathrm{C}-\mathrm{T}$ \\
\hline 14 & SE & $-\mathrm{TC}$ & ------ & ---------- \\
\hline 18 & $\mathrm{C}$ & $-\mathrm{TC}$ & $-\mathrm{CC}---$ & $\mathrm{TC}--\mathrm{A}---\mathrm{A}-$ \\
\hline 19 & $\mathrm{C}$ & $-\mathrm{TC}$ & $-\mathrm{CC}---$ & $-------C-T$ \\
\hline 21 & NE & $-\mathrm{TC}$ & $\mathrm{C}-\mathrm{C}---$ & $-----\mathrm{C}----$ \\
\hline 23 & $\mathrm{C}$ & $-\mathrm{TC}$ & $--\mathrm{CT}--$ & $--------A-$ \\
\hline 24 & SE & $-\mathrm{TC}$ & $--\mathrm{C}-\mathrm{T}-$ & $--\mathrm{T}------\mathrm{T}$ \\
\hline 26 & $\mathrm{NE}$ & $-\mathrm{T}-$ & $--\mathrm{C}---$ & $-----\mathrm{C}----$ \\
\hline 28 & $\mathrm{NE}$ & $-\mathrm{T}-$ & $--\mathrm{C}---$ & $-------C-T$ \\
\hline 36 & $\mathrm{NE}$ & $-\mathrm{TC}$ & ------ & ----------- \\
\hline $41 / 42 / 45$ & W, EU, AU & TTC & $--\mathrm{C}---$ & $---------\mathrm{T}$ \\
\hline 44 & EU & TTC & $--\mathrm{C}--\mathrm{T}$ & $-------C-T$ \\
\hline 43 & W, EU & TTC & $--\mathrm{C}--\mathrm{T}$ & $---------T$ \\
\hline
\end{tabular}

Figure 2 shows the haplotype network for the combined dataset. Most of the genetic variability is found in the USA, with two groups outside the USA: a tightly defined group consisting of haplotype 33 equating with Group A, and a more broadly defined group of haplotypes 41-45 equating with Group B, echoing the analysis of Brewer \& Milgroom (2010). One of the New Zealand groups is an exact match to haplotype 33 (A-33). This type was found only on table grape samples from Christchurch in both 2014 and 2015. B-NZ1 matches types 41/42/45 within Group B. B-NZ2 does not match any of the existing haplotypes but is grouped with haplotypes 41-45 (Group B). B-NZ1 and B-NZ2 differ from each other in only a single position in the present set of markers, but consistently so. Of the samples analysed, only B-NZ2 was associated with chasmothecia. B-NZ1 was consistently detected in vineyards or blocks reported by their viticulturalists to be exhibiting less dense infection than the vineyards from which B-NZ2 was detected. Multiple samples from the same vineyard were associated with a single type, except where different cultivars in different blocks were sampled within the same vineyard. Again, in these cases B-NZ1 was associated with reportedly less severe infections than B-NZ2.

Sixteen samples from two vineyards in Auckland were analysed for the presence of mating type idiomorphs. The samples were from leaf lesions and a number contained a mixture of mating types, as might be expected from samples collected in this way. The resulting mating type distribution is shown in Table 3.

Populations comprising group B-NZ1 isolates were dominated by MAT1-1 with only a single sample having the MAT1-2 idiomorph, whereas populations comprising group B-NZ2 isolates had a 6:5 ratio of MAT1-1: MAT1-2 mating types.

\section{DISCUSSION}

These data, although not statistically robust, support the existence of two Group B haplotypes in New Zealand, with B-NZ2 populations containing both mating types, and B-NZ1 consisting 
Figure 2 The haplotype network for combined data in Table 1. The thickness of the edges is a measure of bootstrap support

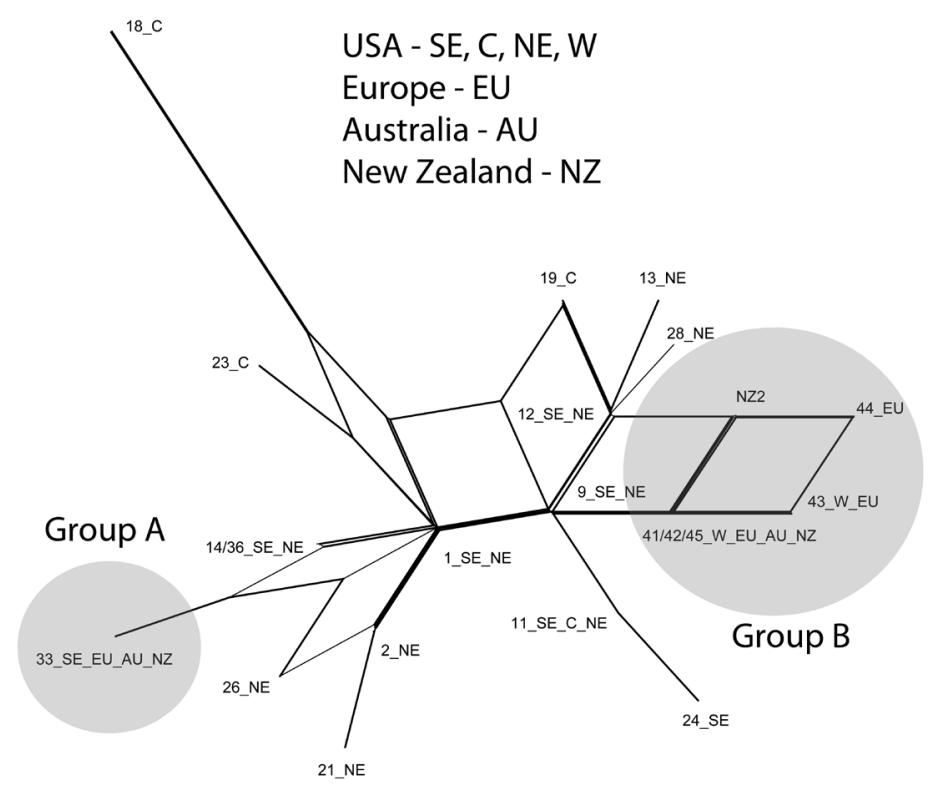

Table 3 Mating type distribution in 16 Auckland samples, based on PCR-based markers from Brewer et al. (2011). \pm indicates a faint band.

\begin{tabular}{llcc}
\hline Isolate & Group & MAT1-1 & MAT1-2 \\
\hline BB1 & B-NZ1 & \pm & \\
BB2 & B-NZ1 & + & \\
BB3 & B-NZ1 & + & \\
BB4 & B-NZ1 & \pm & \\
BB5 & B-NZ1 & & + \\
BB6 & B-NZ1 & + & \\
BB7 & B-NZ1 & + & \\
VM1 & B-NZ2 & + & \\
VM2 & B-NZ2 & + & \\
VM3 & B-NZ2 & + & + \\
VM4 & B-NZ2 & \pm & \\
VM5 & B-NZ2 & & + \\
VM6 & B-NZ2 & \pm & + \\
VM7 & B-NZ2 & + & \\
VM8 & - & & \pm \\
VM9 & B-NZ2 & & + \\
\hline
\end{tabular}

primarily of MAT1-1. The B-NZ2 haplotype has not previously been reported in other countries although that may be due to insufficient sampling.

Field observation of chasmothecia linked to sequenced strains, and the mating type ratio, indicate that only B-NZ2 is regularly sexually reproducing, although it is interesting to note the existence of a single B-NZ1 sample containing MAT1-2 in the present data.

Work elsewhere has shown that early season 'flag shoots' may harbour both Group A and Group B populations, and that Group A populations, although present at the beginning of the season, are typically absent at the end of the season (Montarry et al. 2009). The absence of Group A populations from the present vineyard samples may be due to timing of sampling. These populations may have persisted in the garden vine samples because they were not treated by fungicides. These data suggest that late season vineyard infections that remain asexual are likely to be Group B-NZ1 rather than residual Group A. In this respect it is interesting to note indications that a lower initial population of Group A relative to Group B results in a better late season control outcome (Montarry et al. 2009).

There is currently no direct evidence to support or contradict the emergence of the sexual form as being due to a recent incursion of a compatible Group B mating strain. A recent incursion is a likely scenario if this strain is also present overseas and not unique to New Zealand. However, it is also possible that a compatible mating strain has been present in New 
Zealand for some time, for example, associated with non-commercial vines distant from commercial vineyards.

Further work is required to establish the temporal and spatial distribution of B-NZ1 and B-NZ2 in New Zealand, subsequent chasmothecia formation, any potential niche differentiation, and the associated mating type ratios, together with relative pathogenicity of these groups. In New Zealand the application of predictive modelling of chasmothecia formation (e.g. Legler et al. 2014), subsequent improved disease management measures, cultivar susceptibility, and the potential emergence of fungicide resistance, all require a much better understanding of the fundamental character of the New Zealand populations of E. necator.

\section{ACKNOWLEDGEMENTS}

The following individuals are thanked for advice and for arranging the provision of samples: Peter Wood, Plant \& Food Research, Hawke's Bay; Sioban Harnett, Whitehaven Wine Company, Marlborough; Chris Henry, Henry Manufacturing Limited, Napier; Ned Corfield, Babich Wines; Brett Donaldson, Villa Maria. This research was supported by Plant \& Food Research and Landcare Research through core funding from the Science and Innovation group of the New Zealand Ministry of Business, Innovation and Employment.

\section{REFERENCES}

Araya C, Rosales IM, Mendez MA, Delmotte F 2014. Identification and geographic distribution of genetic groups of Erysiphe necator in Chilean vineyards. Vitis 53: 163-165.

Brewer MT, Milgroom MG 2010. Phylogeography and population structure of the grape powdery mildew fungus, Erysiphe necator, from diverse Vitis species. BMC Evolutionary Biology 10: 268.
Brewer MT, Cadle-Davidson L, Cortesi P, Spanu PD, Milgroom MG 2011. Identification and structure of the mating-type locus and development of PCR-based markers for mating type in powdery mildew fungi. Fungal Genetics and Biology 48: 704-713.

Gadgil PD 2005. Fungi on Trees and Shrubs in New Zealand. Fungi of New Zealand Volume 4. Fungal Diversity Press, Hong Kong.

Gadoury DM, Wilcox WF, Rumbolz J, Gubler WD 2012a. Powdery Mildew. In: Wilcox WF, Gubler WD, Uyemoto J ed. Compendium of Grapevine Diseases (2nd edn.) APS Press, St. Paul, Minn., USA.

Gadoury DM, Cadle-Davidson L, Wilcox WF, Dry IB, Seem RC, Milgroom MG 2012b. Grapevine powdery mildew (Erysiphe necator): a fascinating system for the study of the biology, ecology, and epidemiology of an obligate biotroph. Molecular Plant Pathology 13: 1-16.

Hudson DH, Bryant D 2006. Application of phylogenetic networks in evolutionary studies. Molecular Biology and Evolution 23: 254-267.

Johnston PR, Cooper JA, Park D, Sutherland PW, Wood PN 2014. Sexual state of grape powdery mildew (Erysiphe necator) newly recorded for New Zealand. New Zealand Plant Protection 67: 324 (abstract only).

Legler SE, Caffi T, Rossi V 2014. A model for the development of Erysiphe necator chasmothecia in vineyards. Plant Pathology 63: 911-921.

Montarry J, Cartolaro P, Richard-Chevera S, Delmotte F 2009. Spatio-temporal distribution of Erysiphe necator genetic groups and their relationship with disease levels in vineyards. European Journal of Plant Pathology 123: 61-70. 